\title{
Cor triatriatum sinister - a rare cause of right heart failure
}

\author{
Vlatka Rešković Lukšić゙, Margarita Brida, Blanka Glavaš Konja, Joško Bulum, Alexander Ernst, \\ Darko Anić, Jadranka Šeparović Hanževački \\ University of Zagreb School of Medicine, University Hospital Centre Zagreb, Zagreb, Croatia
}

\begin{abstract}
A 40-year-old male was admitted to our Clinic for evaluation of pulmonary arterial hypertension. Transthoracic (TTE) and transesophageal (TEE) two and three-dimensional echocardiography revealed obstructive membrane in the left atrium with small fenestration of only few millimeters, pulmonary artery pressure (PAP) of $60 \mathrm{mmHg}$ and moderately dilated and hypertrophied right ventricle (RV). Late presentation led us to look for concomitant anomalies, so a partial anomalous left pulmonary venous connection was found. The diagnosis was confirmed by computed tomography (MSCT) upper left pulmonary vein (LUPV) was drained into left brachiocephalic vein via vertical vein, and no lung anomalies were found. On coronary angiography, separate origins of the left anterior descending and circumflex artery were shown. The patient was referred to a cardiac surgeon, but he refused an operative correction at the time. Three years later, he was admitted because of dyspnea on exertion and clinical signs of right sided heart failure. On TTE, impairment of RV function was found, with severe RV dilatation and PAP of $90 \mathrm{mmHg}$. Cardiac magnetic resonance revealed no sig-

Received: $30^{\text {th }}$ Apr 2014

*Address for correspondence: Klinički bolnički centar Zagreb, Kišpatićeva 12, HR10000 Zagreb, Croatia.

Phone: +385-91-5612-526

E-mail: vlatka.reskovic@gmail.com
\end{abstract}

nificant amount of RV fibrosis, and by right heart catheterization, pulmonary vascular resistance index (PVRI) of 1.45 Wood was calculated. Left-to-right shunt was estimated by radionuclide angiocardiography to $26-30 \%$. After medical stabilization, surgical resection of intraatrial membrane and LUPV reconnection into the left atrium appendage was performed. One month after the operation, the patient was asymptomatic and positive remodeling of $\mathrm{RV}$, normal flow in the left atrium and PAP of $23 \mathrm{mmHg}$ were found.

Cor triatriatum sinister is a very rare condition, especially in combination with anomalous pulmonary venous connection, so it is essential to search for concomitant anomalies. In the patient with signs of RV failure, multimodality approach was used to estimate the RV function. The calculation of PVRI was very important in making a decision whether this patient was operable. Some congenital causes of RV heart failure, such as cor triatriatum with anomalous pulmonary venous connection are important to be recognized in adults since they are surgically correctable due to low PVR. Apart from the diagnosis, multidisciplinary approach is also necessary in the assessment of RV function and PVR, key determinants in successful operation.

KEYWORDS: cor triatriatum sinister, right heart failure, anomalous pulmonary venous connection.

CITATION: Cardiol Croat. 2014;9(5-6):240.

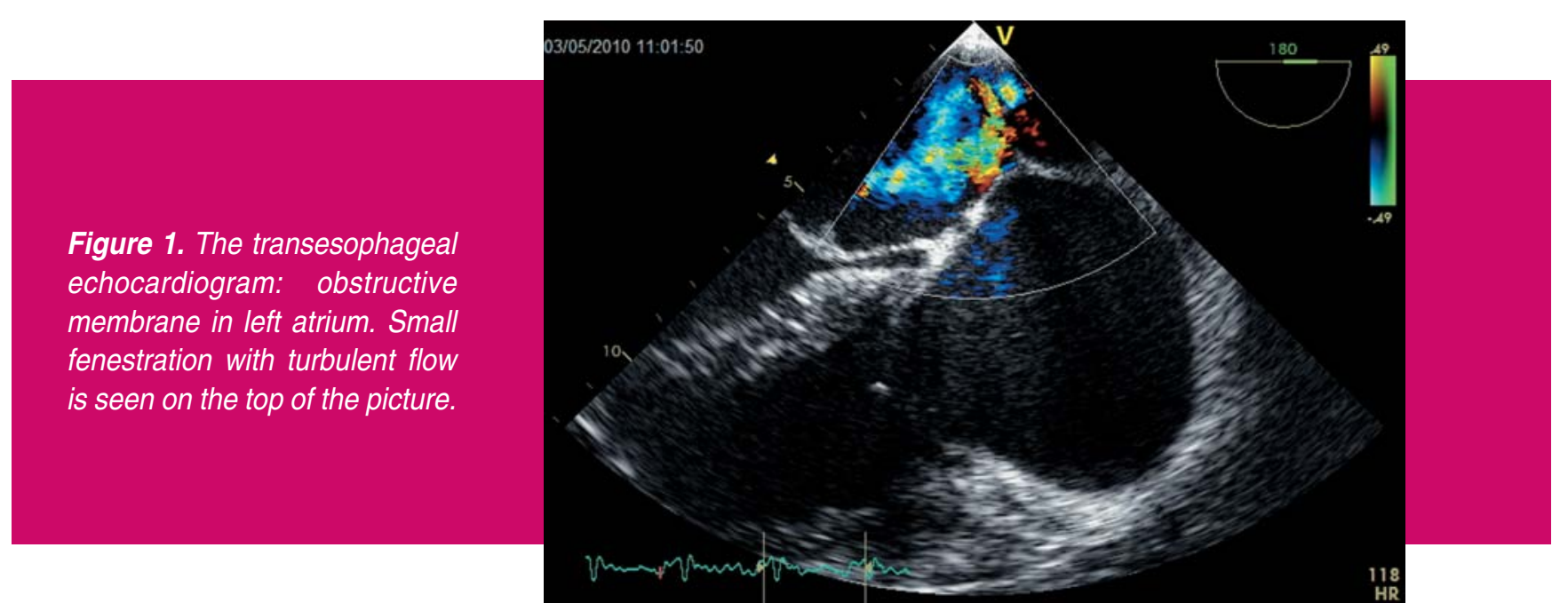

\section{Literature}

1. Hanna R, Chen MA, Gill EA. Cor triatriatum evaluated by real time 3D TEE. Echocardiography. 2011;28(6):E125-8.

2. Hamdan R, Mirochnik N, Celermajer D, Nassar P, Iserin L. Cor Triatriatum Sinister diagnosed in adult life with three dimensional transesophageal echocardiography. BMC Cardiovasc Disord. 2010 Oct 28;10:54.

3. Thakrar A, Shapiro MD, Jassal DS, Neilan TG, King MEE, Abbara S. Cor triatriatum: the utility of cardiovascular imaging. Can J Cardiol. 2007;23(2):143-5 